\title{
Ground-Motion Relations for Eastern North America
}

\author{
by Gail M. Atkinson and David M. Boore
}

\begin{abstract}
Predictive relations are developed for ground motions from eastern North American earthquakes of $4.0 \leqq \mathbf{M} \leqq 7.25$ at distances of $10 \leqq R \leqq 500$ $\mathrm{km}$. The predicted parameters are response spectra at frequencies of 0.5 to 20 $\mathrm{Hz}$, and peak ground acceleration and velocity. The predictions are derived from an empirically based stochastic ground-motion model. The relations differ from previous work in the improved empirical definition of input parameters and empirical validation of results. The relations are in demonstrable agreement with ground motions from earthquakes of $\mathbf{M} 4$ to 5 . There are insufficient data to adequately judge the relations at larger magnitudes, although they are consistent with data from the Saguenay (M 5.8) and Nahanni (M 6.8) earthquakes. The underlying model parameters are constrained by empirical data for events as large as $\mathbf{M} 6.8$.
\end{abstract}

\section{Introduction}

Ground-motion relations describing peak ground motions and response spectra as functions of earthquake magnitude and distance are of paramount importance in the assessment of earthquake hazard to engineered structures. In recent years, ground-motion relations for eastern North America (ENA) have been based on a stochastic model (e.g., Atkinson, 1984; Boore and Atkinson, 1987; Toro and McGuire, 1987; EPRI, 1988; Atkinson and Boore, 1990). The model has its origins in the work of Hanks and McGuire (1981), who showed that observed high-frequency ground motions can be characterized as finite-duration bandlimited Gaussian noise, with an underlying amplitude spectrum as specified by a simple seismological model of source and propagation processes. Their model has fundamentally changed the way in which ground-motion relations are developed by providing a simple physical framework with which to interpret empirical observations.

For western North America (WNA), it has been shown that the Brune (1970) source model, with a stress parameter of about 100 bars, provides accurate estimates of average ground motions when used in conjunction with the stochastic model (Hanks and McGuire, 1981; Boore, 1983; Boore et al., 1992). For ENA, previous applications (referenced above) have also assumed the 100-bar Brune source model. This assumption was justified based on inferences from a few moderate (M 4 to 5) ENA events (Atkinson, 1984; 1989) and teleseismic data from larger historical earthquakes (Somerville et al., 1987). The 1988 Saguenay, Quebec, earthquake (M 5.8), by contrast, differed dramatically from the predictions of the simple Brune model (Boore and Atkinson, 1992), raising questions concerning the validity of the underlying source model for large events and the adequacy of our knowledge concerning ENA source spectra. These concerns were heightened by the work of Boatwright and Choy (1992), who showed that the teleseismic spectra of large intraplate events generally depart from the Brune model; most intraplate earthquakes appear to have two corner frequencies.

Recent earthquakes have also highlighted wavepropagation issues that were not addressed in the development of previous ENA ground-motion relations. Theoretical studies of wave propagation in a layered crust indicate that the decay of ground-motion amplitudes may be depth dependent (EPRI, 1993). Furthermore, the decay pattern may be significantly disrupted in the distance range from about 60 to $120 \mathrm{~km}$; in this distance range the direct wave is joined by the first postcritical reflections from internal crustal interfaces and the Moho discontinuity (Burger et al., 1987). It has been suggested that the "Moho bounce" was at least partly responsible for the large ground-motion amplitudes observed at distances near $100 \mathrm{~km}$ during the Saguenay (Somerville $e t$ $a l ., 1990)$ and Loma Prieta (Fletcher and Boatwright, 1991; Campbell, 1991) earthquakes.

Recent empirical studies of over 1500 seismograms from ENA earthquakes in the magnitude range from 3.5 to 6.8 have provided significant new information on ENA ground-motion processes. The recent studies show that (1) source spectra for ENA earthquakes of $\mathbf{M}>4$ deviate significantly from the Brune 100-bar model (Atkinson, 1993a); (2) the attenuation of spectral amplitudes is slightly disrupted by the transition from direct-wave to $L g$-wave spreading, suggesting a hinged trilinear form for the attenuation curve (Atkinson and Mereu, 1992); (3) the du- 
ration of motion increases with distance in a complex manner (Atkinson, 1993b); and (4) the ratio of horizontal-to-vertical component ground motions is frequency dependent, but independent of distance (Atkinson, 1993b). These studies were based on data derived mostly from earthquakes in southeastern Canada and the northeastern United States. Wave-propagation studies suggest that ground-motion relations should show little regional variability over most of ENA, with the exception of the Gulf Coast region (EPRI, 1993). Therefore ground-motion relations derived from data in southeastern Canada and the northeastern United States should be applicable over most of ENA.

In this article, we use the new information on ENA source and attenuation processes to update our 1987 ground-motion relations. The method used to develop the ground-motion relations is briefly reviewed, with emphasis on the data defining each of the input parameters. Predictive relations are developed for peak ground motion and response spectra for rock sites and compared to available ground-motion data.

\section{Approach}

\section{Review of the Basic Method}

The ground-motion predictions are based on the stochastic model, in which ground motion is modeled as bandlimited Gaussian noise; the radiated energy is assumed to be evenly distributed over a specified duration. The method is quite general and can be used to predict many amplitude and instrument-response parameters (Boore, 1983).

The method begins with the specification of the Fourier amplitude spectrum of ground acceleration as a function of seismic moment and distance, $A\left(M_{0}, R, f\right)$, which can be represented by

$$
A\left(M_{0}, R, f\right)=E\left(M_{0}, f\right) D(R, f) P(f) I(f) .
$$

The term $E\left(M_{0}, f\right)$ is the earthquake source spectrum for a specified seismic moment (i.e., Fourier spectrum of the ground acceleration at a distance of $1 \mathrm{~km})$, and $D(R$, $f$ ) is a diminution function that models the geometric and anelastic attenuation of the spectrum as a function of hypocentral distance $(R)$ and frequency $(f)$. The term $P(f)$ is a high-cut filter that rapidly reduces amplitudes at high frequencies; it may be based on either the $f_{\max }$ model (Hanks, 1982) or the kappa model (Anderson and Hough, 1984). The term $I(f)$ is a filter used to shape the spectrum to correspond to the particular ground-motion measure of interest. For example, for the computation of response spectra $I$ is the response of an oscillator to ground acceleration. For free-field ground-motion parameters, I is simply

$$
I(f)=1 /(2 \pi f)^{p},
$$

where $p=0$ for acceleration, 1 for velocity, or 2 for displacement.

The time-domain implementation of the stochastic method used in this study begins with the generation of a windowed acceleration time series comprised of random Gaussian noise with zero mean amplitude; the variance is chosen such that the spectral amplitude is unity on average. The duration of the window is specified as a function of magnitude and distance. The spectrum of the windowed time series is multiplied by the desired amplitude spectrum $\left[A\left(M_{0}, R, f\right)\right.$ from equation (1)]. The filtered spectrum is then transformed back into the time domain to yield a simulated earthquake record for that magnitude and distance. Details of the method are given in Boore (1983) and Boore and Atkinson (1987).

\section{Input Parameters}

The input parameters for the method include all terms of equation (1), and the duration of motion. The simulations will apply to the random horizontal component of the shear phase of ground motion.

The earthquake source spectrum $\left[E\left(M_{0}, f\right)\right]$ for the horizontal component of ground motion is given by a functional form that represents the addition of two Brune spectra (Atkinson, 1993a):

$$
\begin{aligned}
E\left(M_{0}, f\right)= & C(2 \pi f)^{2} M_{0}\left\{(1-\epsilon) /\left[1+\left(f / f_{A}\right)^{2}\right]\right. \\
& \left.+\epsilon /\left[1+\left(f / f_{B}\right)^{2}\right]\right\}
\end{aligned}
$$

where $C=R_{p} F V /\left(4 \pi \rho \beta^{3} R\right)$, with $R=1 \mathrm{~km}, R_{p}=$ average radiation pattern $(=0.55), F=$ free-surface amplification $(=2.0), V=$ partition onto two horizontal components $(=0.71), \rho=$ crustal density $\left(=2.8 \mathrm{gm} / \mathrm{cm}^{3}\right)$, and $\beta=$ shear-wave velocity $(=3.8 \mathrm{~km} / \mathrm{sec})$. The values for the crustal constants are based on the seismic reflection/refraction data of Mereu et al. (1986) for southeastern Canada, for the average focal depth of events in the region $(10 \mathrm{~km})$. The choice of reference depth for $\beta$ is not critical because there is little dependence of shearwave velocity on depth for ENA hard-rock sites; this also implies that near-surface amplification due to impedance contrasts is negligible for hard-rock sites (Boore and Atkinson, 1987). The parameters $\epsilon, f_{A}$, and $f_{B}$ are functions of seismic moment, given for $4 \leqq \mathbf{M} \leqq 7$ by

$$
\begin{aligned}
\log \epsilon & =2.52-0.637 \mathbf{M} \\
\log f_{A} & =2.41-0.533 \mathbf{M} \\
\log f_{B} & =1.43-0.188 \mathbf{M} .
\end{aligned}
$$

Equation (3) was derived by analysis of spectral data from a variety of sources, covering the frequency range from 1 to $10 \mathrm{~Hz}$. The data set included 22 ENA earthquakes of $4 \leqq \mathbf{M}<7$. Source spectral amplitudes, seismic mo- 
ments, and corner frequencies $\left(f_{A}\right.$ and $\left.f_{B}\right)$ were inferred from regional seismographic data (Street and Turcotte, 1977; Atkinson and Mereu, 1992), intensity data (Atkinson, 1993a), and teleseismic data (Somerville et al., 1987; Boatwright and Choy, 1992). The use of equation (3) for magnitudes as large as 7.25 represents a slight extrapolation.

Figure 1 compares the new source model to the 100bar Brune model used in our 1987 ground-motion relations. The complexity of shape is required in order to reconcile observations over the $1-$ to $10-\mathrm{Hz}$ frequency band with the seismic moment of the events. Equation (3) is the simplest functional form that matches both spectral amplitudes and corner frequencies. It is an empirical representation rather than a theoretical model. The rather dramatic reduction of spectral amplitudes at intermediate frequencies, relative to the Brune model, is an important implication of equation (3). This feature is a consequence of the spectral-amplitude and corner-frequency data; it is not an artifact of the selected functional form. The sag in spectral amplitudes at intermediate frequencies is driven by the observation that $1-\mathrm{Hz}$ spectral amplitudes are smaller than those that would be inferred by a straight-line interpolation between the moment end of the spectrum and its high-frequency end.

The amplitudes predicted by equation (3) are constrained by data for frequencies of $1 \mathrm{~Hz}$ and greater, for $4 \leqq \mathbf{M}<7$. Examination of strong-motion data from the Saguenay (M 5.8) and Nahanni (M 6.8) earthquakes

\section{ENA Model vs. Brune 100 bars $M=5,6,7$}

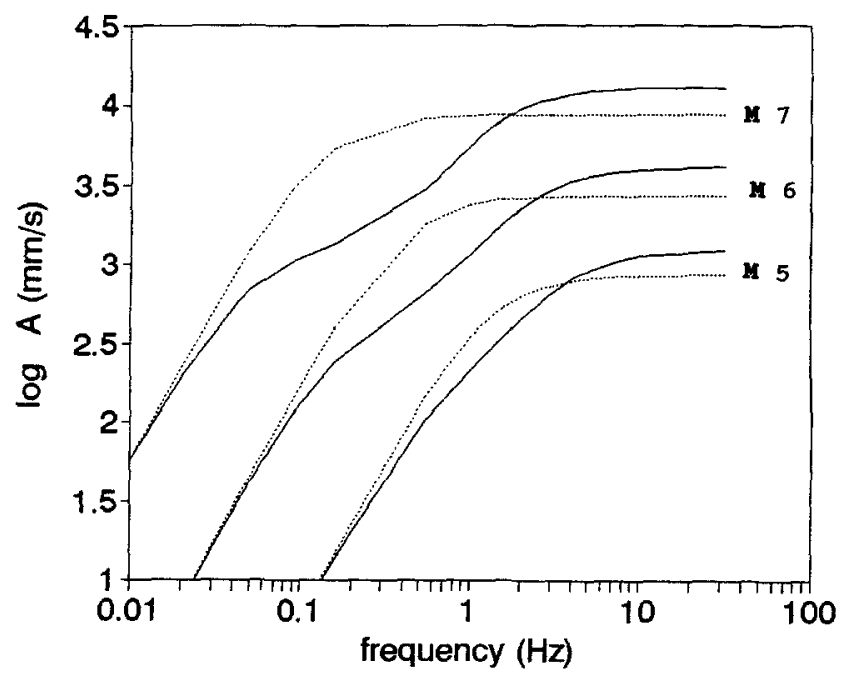

- Proposed model -......... Brune 100 bars

Figure 1. Comparison of horizontal-component source spectra $(R=1 \mathrm{~km})$ for the ENA empirical model with those of the 100-bar Brune model, for M 5, 6, and 7 (from Atkinson, 1993a). suggests that the shape is appropriate for frequencies at least as low as $0.5 \mathrm{~Hz}$; for these earthquakes the observed ratio of 1 to $0.5 \mathrm{~Hz}$ spectral amplitudes is well predicted by equation (3). The amplitudes cannot be verified for lower frequencies, and therefore the groundmotion predictions are restricted to $f \geqq 0.5 \mathrm{~Hz}$.

The attenuation of spectral amplitudes with distance $[D(R, f)]$ is prescribed by a minor variation of the hinged trilinear form of Atkinson and Mereu (1992). Based on 1500 seismograms from 100 earthquakes of magnitude $m_{N} 3$ to 6.5 , they found that spectral-amplitude decay due to geometric spreading is approximately independent of frequency. The best fit to the data is given by $R^{-1.1}$ for distances from $R=10$ to $R=70 \mathrm{~km}$. From $R=70$ to $R=130 \mathrm{~km}$, there is no apparent geometric spreading. For $R>130 \mathrm{~km}$, spectral-amplitude decay due to geometric spreading can be modeled as $R^{-0.5}$. The associated $Q$ model is $Q=670 f^{0.33}$, where the anelastic attenuation of spectral amplitudes is then given by $\exp [-\pi f R / \beta Q(f)]$. The overall attenuation is obtained as the product of the geometric and anelastic attenuation terms. There is little apparent dependence of the attenuation on focal depth.

In this study, we have modified the form slightly by assuming $R^{-1}$ geometric spreading to $70 \mathrm{~km}$, rather than $R^{-1}$ (then $R^{0.0}$ from 70 to $130 \mathrm{~km}$, then $R^{-0.5}$ for $R>$ $130 \mathrm{~km}$ ). The associated $Q$ model, derived by refitting the data of Atkinson and Mereu (1992), is $Q=680 f^{0.36}$. The empirical attenuation is applicable for distances large enough to allow the source to be treated as a point. Finite-fault effects might alter the observed attenuation in the near-source region, but this would only be significant for large $(\mathbf{M}>6.5)$ earthquakes.

For the high-cut filter, we use (Boore, 1986)

$$
P(f)=\left[1+\left(f / f_{\max }\right)^{8}\right]^{-1 / 2},
$$

where $f_{\max }$ is the high-frequency cutoff proposed by Hanks (1982). For ENA we have assumed a value of $f_{\max }=50$ $\mathrm{Hz}$ based on a review of very limited data. An alternative would be to use the kappa filter suggested by Anderson and Hough (1984):

$$
P(f)=\exp (-\pi k f)
$$

where $k$ is the high-frequency decay slope on plots of $\log$ spectra versus frequency (for near-source distances for which anelastic attenuation is negligible). The kappa filter is not as abrupt as the $f_{\max }$ filter; it represents a gradual diminution of spectral amplitudes with increasing frequency, rather than an upper limit on frequency. Many of the ENA spectra that we have reviewed are apparently flat out to frequencies of $20 \mathrm{~Hz}$, above which there are no data (we approach the upper corner frequency of the recording instruments). In this case, a meaningful estimate of either kappa or $f_{\max }$ is not really 
possible. This is illustrated for several typical ECTN records (at $R<100 \mathrm{~km}$ ) in Figure 2. We have therefore chosen to use the $f_{\max }$ filter with a high cutoff value (50 $\mathrm{Hz}$ ), to avoid artificially diminishing high-frequency amplitudes. Beware that predictions for frequencies above $20 \mathrm{~Hz}$, and peak ground acceleration, depend critically on this parameter. If very high frequencies are of interest, more information is needed on $P(f)$. For the present application, we assume that frequencies above $20 \mathrm{~Hz}$ are not of engineering interest.

The final input element of the stochastic predictions is the duration model. The duration model generally has two terms,

$$
T=T_{0}+b R
$$

where $T_{0}$ is the source duration and $b R$ represents a distance-dependent term that accounts for dispersion. For the source duration, we assume that $T_{0}=1 /\left(2 f_{A}\right)$ (Boatwright and Choy, 1992), where $f_{A}$ is the lowest corner frequency in the source spectrum, as given by equation

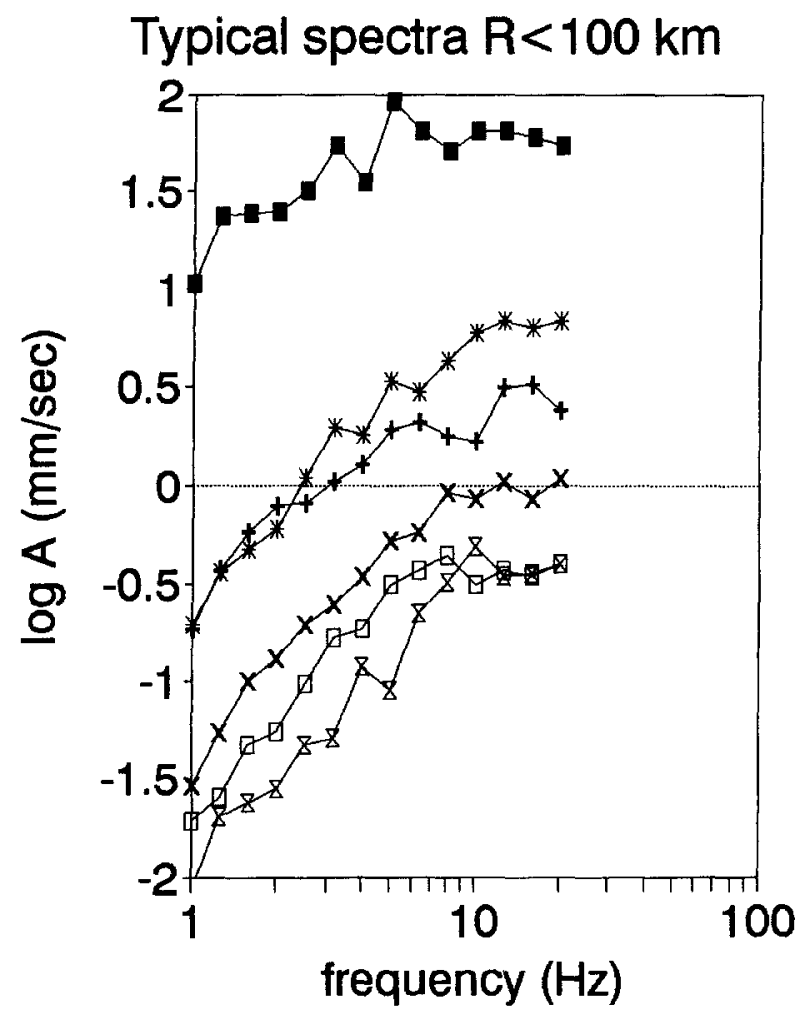

MN 5.1 GRQ — MN 4.1 OTT - MN 4.1 GSQ

$\rightarrow \mathrm{MN} 3.6 \mathrm{LPQ}-\mathrm{MN} 3.4 \mathrm{GRQ}-\mathrm{MN} 3.3 \mathrm{WBO}$

Figure 2. Typical plots of acceleration spectra versus frequency for ENA events near the source, showing the apparent lack of high-frequency decay (kappa).
(5). This source-duration estimate is compatible with the ENA source-duration data of Somerville et al. (1987). The source durations given by $1 /\left(2 f_{A}\right)$ are within $10 \%$ of those used in our previous (1987) study. (In 1987 we assumed a source duration of $1 / f_{0}$, where $f_{0}$ was the corner frequency of the Brune (1970) model; note $f_{A}<f_{0}$ $<f_{B}$ ).

The empirical basis for the distance-duration term is the collection of 1500 ECTN seismographs used to define the attenuation function. Atkinson (1993b) computed, for each record, the duration that matches the observed relationship between the peak ground velocity (PGV) and the Fourier spectrum of velocity, using random-processtheory equations. For this study we have taken a closer look at these duration data. Because most of the earthquakes in the ECTN database are small, the distance-dependent term of equation (9) dominates the duration; the $b R$ term can therefore be determined with confidence by subtracting a simple estimate of $T_{0}$ from the total duration. For this purpose, we assume $T_{0}=1 / f_{0}$, rather than $1 /\left(2 f_{A}\right)$, since most events in the duration data set are too small $(\mathbf{M}<4)$ for the two-corner model to be applicable. These distance-dependent duration terms ( $T$ $T_{0}$ ) are averaged within narrow distance bins and shown in Figure 3. The distance dependence of duration is modeled as trilinear, using the transition distances 70 and $130 \mathrm{~km}$ for consistency with the attenuation model; the slope $b$ is 0.16 for $10 \leqq \mathbf{R} \leqq 70 \mathrm{~km},-0.03$ for $70<$ $R \leqq 130 \mathrm{~km}$, and 0.04 for $130<R<1000 \mathrm{~km}$ (a slope of zero is assumed for $R<10 \mathrm{~km}$ ). The negative slope in the transition zone from direct wave to $L g$ phase ( 70 to $130 \mathrm{~km}$ ) is due to the additional energy that is injected

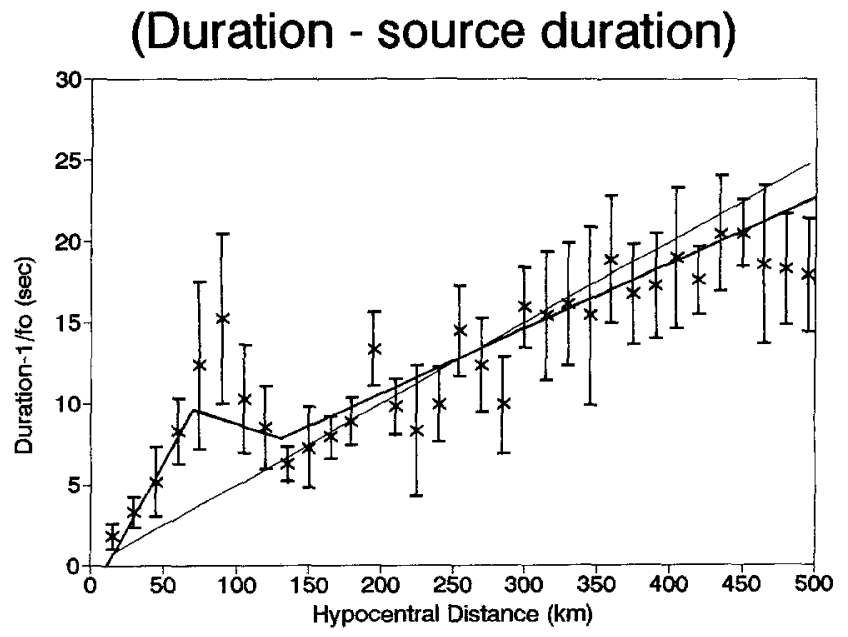

Figure 3. Mean of the rms duration minus the source duration, averaged by $15-\mathrm{km}$ distance bins. Vertical bars show $90 \%$ confidence limits on the estimate of the mean. Trilinear line is that used in the stochastic simulations; distance duration is assumed to equal zero at $R \leqq 10 \mathrm{~km}$. Simple straight line is $0.05 R$, the distance-duration term used in previous (1987 and 1990) simulations. 
within the time window of the signal as the "Moho bounce" rays arrive. The random-process model requires a decrease in duration in order to correctly predict the enhanced time-domain amplitudes that result.

\section{Choice of Magnitude Scale}

The above equations provide all the information needed to simulate the horizontal component of ground motion for hard-rock sites as a function of moment magnitude and hypocentral distance. We choose to develop the ground-motion equations in terms of moment magnitude, rather than the more widely catalogued (but more ambiguously defined) Nuttli magnitude $\left(m_{N}\right)$. We prefer $\mathbf{M}$ because it has a simple physical interpretation (Hanks and Kanamori, 1979), and because there is some hope of being able to specify $\mathbf{M}$ for a future expected earthquake based on geological evidence. The $\mathbf{M}$ value has been estimated for most of the large historical ENA earthquakes from special studies. For moderate $\left(m_{N} \leqq\right.$ 6) cataloged events for which no estimates of $\mathbf{M}$ are available, $\mathbf{M}$ can be estimated from the empirical relationship shown in Figure 4 (Atkinson, 1993a):

$$
\mathbf{M}=-0.39+0.98 m_{N} ; \quad m_{N} \leqq 6 .
$$

The standard error of an estimate is 0.15 . This relationship should not be extrapolated to $m_{N}>6$, since theo-

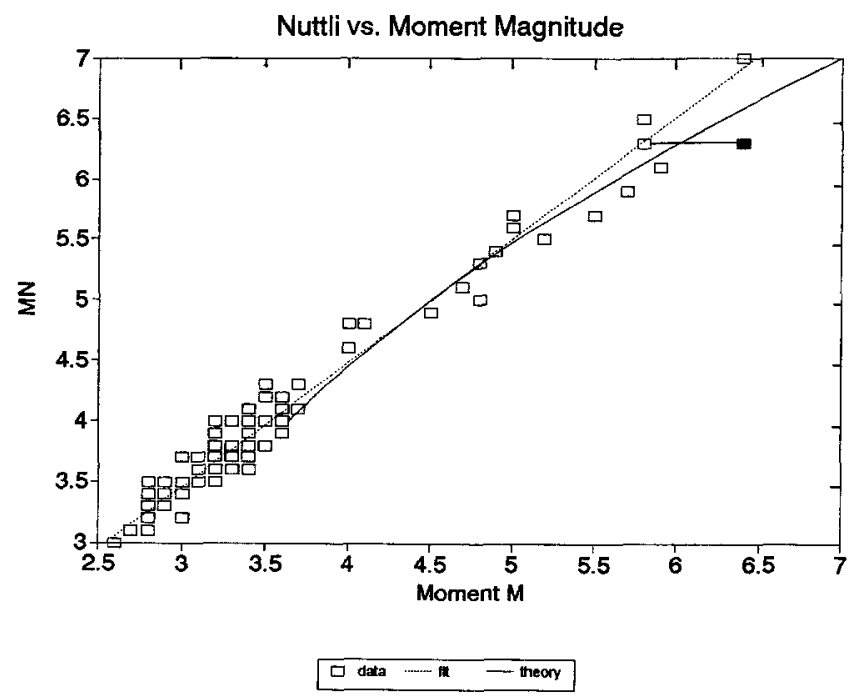

Figure 4. Relationship between $L g$ magnitude $\left(m_{N}\right)$ and moment magnitude $(\mathbf{M})$. Data are from the ECTN (M values of Atkinson, 1993a; $m_{N}$ values from Geophysics Division, Geological Survey of Canada), and from Boore and Atkinson (1987). Dotted line is the least-squares fit to the data [see equation (10)]. Solid line is the theoretical relation of Boore and Atkinson (1987). Line connecting empty to filled square shows alternative $\mathbf{M}$ estimates for the Timiskaming earthquake (from Atkinson, 1993a). retically there is significant curvature to the $m_{N}$ versus $M$ relation at large magnitudes (Boore and Atkinson, 1987). This curvature cannot be defined by the empirical data because of the paucity of large events and the large uncertainties in estimated values of both $\mathbf{M}$ and $m_{N}$ for a few critical historical earthquakes (1925 Charlevoix, 1935 Timiskaming). It can be defined theoretically, but only by making particular assumptions regarding the instrument type and distance at which $m_{N}$ is measured. One such theoretical relation is (Boore and Atkinson, 1987)

$$
\mathbf{M}=2.715-0.277 m_{N}+0.127 m_{N}^{2} .
$$

When $\mathbf{M}$ must be estimated from $m_{N}$, equation (10) should be used for $m_{N} \leqq 5.5$, and equation (11) for $m_{N}>5.5$.

It is straightforward and practical to conduct seismic hazard analyses based on $\mathbf{M}$ rather than $m_{N}$. In fact, the ability to predict $\mathbf{M}$ from $m_{N}$, or vice versa, is implicit in any process that converts the $\mathbf{M}$-based predictive model to an equivalent $m_{N}$-based model. It may be argued that the use of $m_{N}$ should result in lower variability of highfrequency ground motions, since $m_{N}$ is measured at higher frequencies than $M$. Contrary to this expectation, Atkinson (1993a) found that the standard error of the common logarithm of the estimated high-frequency spectral amplitude is 0.17 for predictions based on $\mathbf{M}$, and 0.19 for predictions based on $m_{N}$. This suggests that intermediate-frequency magnitude $\left(m_{N}\right)$ does not predict highfrequency amplitude with any greater precision than does low-frequency magnitude (M). Thus there appears to be no advantage to using $m_{N}$.

If it is desired to make ground-motion predictions based on a magnitude scale that more closely describes high-frequency motions, the high-frequency magnitude scale (m) proposed by Atkinson and Hanks (1995) should be used [see Atkinson (1995) for a discussion of the optimal choice of magnitude scales]. The term $\mathbf{m}$ can be defined for modern events based on seismographic data, or for historical events based on felt area. Since $\mathbf{M}=$ $\mathbf{m}$ on average, by definition, separate ground-motion relations in terms of $\mathbf{m}$ are not required; simply use the observed $\mathbf{m}$ in place of $\mathbf{M}$ in the predictive relations, for frequencies above $f_{B}$. For example, referring to the list of $\mathbf{m}$ values in Table 4 , the high-frequency $(f>2 \mathrm{~Hz})$ amplitudes from the Saguenay earthquake could be predicted from our ground-motion relations using a magnitude of 6.5 .

\section{Ground-Motion Predictions}

\section{Results}

Response spectra (5\% damped pseudo-acceleration, PSA) for frequencies of 0.5 to $20 \mathrm{~Hz}$, and peak ground acceleration (PGA) and velocity (PGV) were simulated for $4.0 \leqq \mathbf{M} \leqq 7.25$, in 0.25 magnitude-unit increments, 
from $R=10 \mathrm{~km}$ to $R=500 \mathrm{~km}$, in increments of 0.1 $\log$ units. Fifty trials were used for each magnitude-distance combination.

The median ground motions for the random horizontal component at rock sites are summarized in the Appendix table. Figure 5 plots the estimated PSA at four frequencies, and PGA and PGV for a range of magnitudes and distances. The figure also shows simple quadratic equations that approximate the estimates for the purposes of seismic hazard calculations. The coefficients of the plotted quadratic prediction equations are listed in Table 1. The equations were obtained by regression of a subset of the simulated ground-motion data. The subset included all distances $(R \leqq 500 \mathrm{~km})$ for large events (M $>6.5)$, but only near distances $(R \leqq 25 \mathrm{~km})$ for small events. Thus the attenuation has been constrained to match the relatively slow decay of motions that is applicable for large earthquakes.

In Figure 5 it is clear that the quadratic equations do not adequately match the shape of the attenuation curve for small-to-moderate events $(\mathbf{M}<5.5)$. For small events, the equations grossly overpredict the simulated amplitudes at distances greater than $30 \mathrm{~km}$, while underpredicting amplitudes at very close $(R<15 \mathrm{~km})$ distances. This was deliberate. The objective was to fit the complex magnitude-dependent shape of the results with a simple functional form that is convenient to use in hazard analyses and is sufficiently accurate in the magnitude-distance ranges that are most significant to seismic hazard analysis in the east. We are willing to accept a large margin of conservatism for small, distant earthquakes because these will not contribute significantly to the seismic hazard.

We tested how well the simple quadratic equations meet this goal by performing some example hazard calculations, using the well-known Cornell-McGuire (Cornell, 1968; McGuire, 1976, 1977) method. We consider three seismicity environments: a low-hazard area with levels of seismicity such as those observed in central Ontario, Michigan, and much of the central United States; a moderate-hazard area such as the Appalachians, western Quebec, and much of the eastern seaboard; and a high-hazard area such as Charlevoix, Quebec, or New Madrid. The assumed seismicity parameters for these three examples are listed in Table 2. The values in Table 2 are "ballpark" figures that do not apply to any specific sites. For each seismic environment, we calculate the median response spectra for exceedence probabilities of 0.002 per annum (p.a.) and 0.0001 p.a., by integrating contributions to the exceedence probability over all magnitudes from $\mathbf{M}=4.5$ to $\mathbf{M}_{x}$ (the maximum magnitude assumed possible for the area), and all distances from $R$ $=10 \mathrm{~km}$ (assumed depth of earthquakes) to $R=500$ $\mathrm{km}$. We compare the seismic-hazard curves obtained using the quadratic ground-motion relations of Table 1 to those obtained using our "exact" ground-motion rela- tions (Appendix table). The latter relations are implemented by building a look-up table into the program that performs the hazard computations; for each magnitudedistance step considered by the hazard program, the appropriate ground-motion value is obtained by interpolation from the table of ground-motion results. The probabilities selected for the comparisons cover the range of typical engineering interest; ground-motion estimates for the 0.002 p.a. probability level are usually used for building-code applications, whereas results for the 0.0001 p.a. probability level are often sought for analysis of critical facilities.

Figure 6 compares the resulting "approximate" (i.e., using the equations) and "exact" (using the table) ground motions for these probabilities; also shown are the corresponding values based on our previous ground-motion relations (Atkinson and Boore, 1990; also applies to Boore and Atkinson, 1987). For cases where the expected motions are relatively large (PGA $>25 \% \mathrm{~g}$ ), the quadratic equations predict the results obtained using the "exact" ground-motion relations accurately (to within 5 to $10 \%$ ). For cases where the expected ground motions are moderate (PGA 10 to $20 \% \mathrm{~g}$ ), the use of the quadratic equations will give ground-motion estimates that are conservative by 20 to $40 \%$ at high frequencies. Small expected ground motions (PGA $\leqq 5 \% g$ ) are grossly overpredicted, but this has no practical significance since these motions would not influence design.

We conclude that the simple quadratic equations will work just fine in seismic hazard analyses in the cases where it matters most. For this reason, we decided not to fit the results to a general polynomial form (we estimated that a fifth-degree polynomial would be required, resulting in a large number of attenuation coefficients for each frequency). For cases where greater accuracy is required, or to avoid conservatism in lowseismicity regions, we recommend referring to the table of results given in the Appendix. We will mail a diskette with our unabridged table of results, with a subroutine for implementing the look-up table approach described above, to anyone who requests one. An alternative approach to avoiding conservatism in hazard analysis would be to use a larger lower-magnitude bound for integration, thus compensating for the overestimation of motions from small events. For example, if a lower-magnitude bound of 5.0, rather than 4.5 , is used in the hazard computations, then the "equation results" match the target "table results" to within about $15 \%$ for cases of moderate expected ground motions. (For cases of very low expected ground motions, a lower-magnitude bound of 5.0 would be too low to capture the events dominating the high-frequency hazard.)

A final point of interest in Figure 6 is the comparison between the results obtained using the new groundmotion relations and those obtained using our previous relations (Atkinson and Boore, 1990; also Boore and At- 
AB94 Simulations vs. Quad. Eqn. $f=1.3 \mathrm{~Hz}$
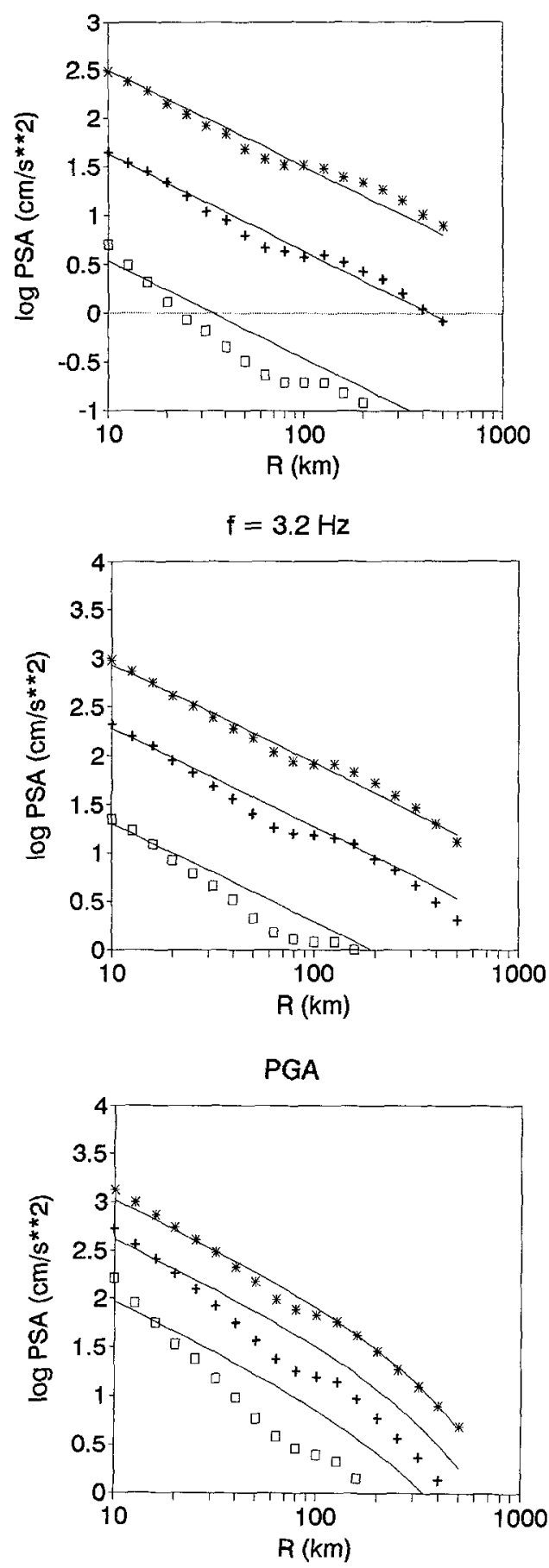

- M $4.0+M 5.5 * M 7.0$
AB94 Simulations vs. Quad. Eqn. $f=0.5 \mathrm{~Hz}$
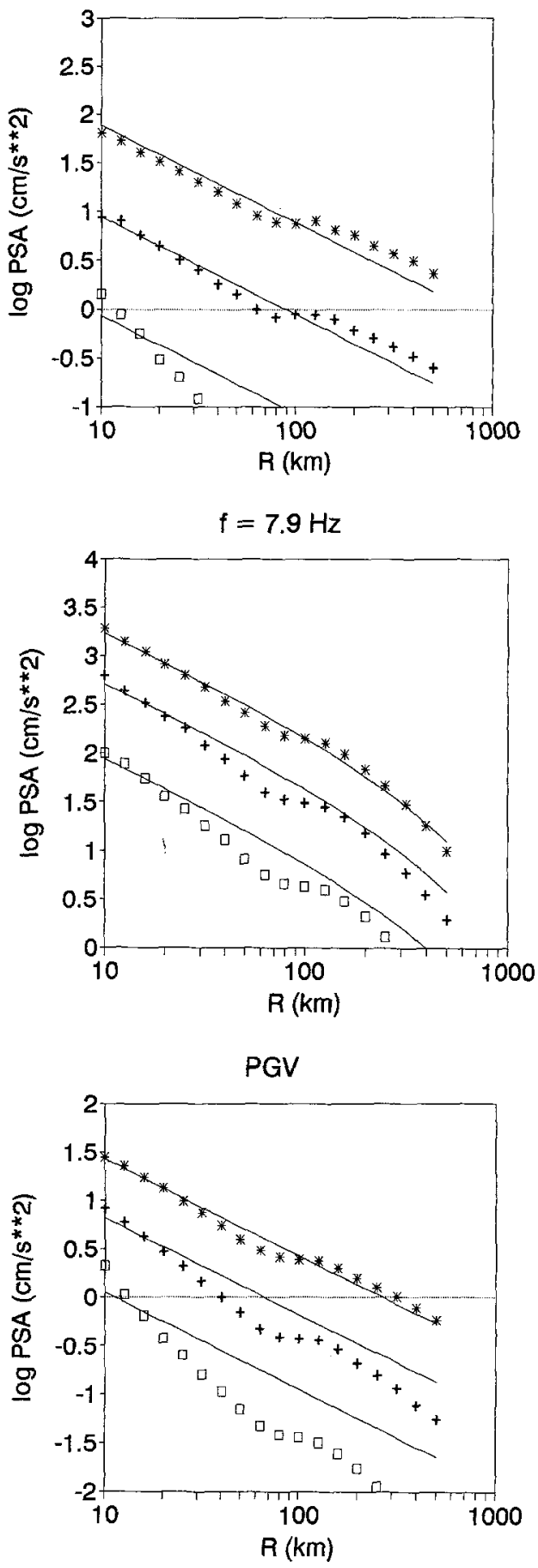

$\mathrm{M} 4.0+\mathrm{M} 5.5 * \mathrm{M} 7.0$

Figure 5. Predicted response spectral values (PSA for 5\% damping) for four frequencies and peak ground acceleration (PGA) and velocity (PGV), for $\mathbf{M} 4.0$ $(\square), 5.5(+)$, and $7.0(*)$. Symbols show ground-motion predictions. Lines show quadratic equations of Table 1 . 
Table 1

Regression Coefficients for the Quadratic Equation log PSA $=c_{1}+c_{2}(\mathbf{M}-6)+c_{3}(\mathbf{M}-6)^{2}-\log R-c_{4} R$

\begin{tabular}{lcccl}
\hline Freguency $(\mathrm{Hz})$ & $c_{1}$ & $c_{2}$ & $c_{3}$ & \multicolumn{1}{c}{$c_{4}$} \\
\hline 0.5 & 2.27 & 0.634 & -0.0170 & 0.0000 \\
0.8 & 2.60 & 0.635 & -0.0308 & 0.0000 \\
1.0 & 2.77 & 0.620 & -0.0409 & 0.0000 \\
1.3 & 2.95 & 0.604 & -0.0511 & 0.0000 \\
2.0 & 3.26 & 0.550 & -0.0640 & 0.0000 \\
3.2 & 3.54 & 0.475 & -0.0717 & 0.000106 \\
5.0 & 3.75 & 0.418 & -0.0644 & 0.000457 \\
7.9 & 3.92 & 0.375 & -0.0562 & 0.000898 \\
10.0 & 3.99 & 0.360 & -0.0527 & 0.00121 \\
13.0 & 4.06 & 0.346 & -0.0492 & 0.00153 \\
20.0 & 4.19 & 0.328 & -0.0477 & 0.00226 \\
PGA & 3.79 & 0.298 & -0.0536 & 0.00135 \\
PGV & 2.04 & 0.422 & -0.0373 & 0.0000 \\
\hline
\end{tabular}

Notes: equation gives PSA, PGA in $\mathrm{cm} / \mathrm{s}^{2}$, and PGV in $\mathrm{cm} / \mathrm{s}$, where PSA is the pseudo-acceleration (5\% damped), for the random horizontal component on rock.

kinson, 1987). Our new information has increased highfrequency $(f>5 \mathrm{~Hz})$ ground-motion estimates significantly. This reflects new knowledge of the potential for high-stress events like the 1988 Saguenay and 1990 Mont Laurier earthquakes. Intermediate-frequency ( $f \leqq 1 \mathrm{~Hz}$ ) motions have decreased, in some cases dramatically, as a consequence of the new source model shape. The relative shift in expected ground motions toward higher frequencies has important implications for seismic hazard evaluations throughout ENA. It may be that the eastern earthquake hazard is mostly restricted to high-frequency structures.

The ground-motion estimates given in the Appendix table, and by the quadratic equations, apply to bedrock sites. For typical ENA deep-soil sites (i.e., dense or stiff soils more than $60 \mathrm{~m}$ in depth), linear analyses indicate that the bedrock values would be amplified by a factor of 1.4 to 2 over most of the frequency range from 0.5 to $10 \mathrm{~Hz}$, as shown in Table 3. Table 3 was produced by comparing the ground-motion equations derived by Boore and Joyner (1991) for deep-soil sites to the equivalent relations derived by Boore and Atkinson (1987) for rock sites. Both sets of relations used the stochastic method, with the same parameter values. The factors are thus relative amplifications; they do not depend heavily on the specific parameter values of the ground-motion simulations. The amplification factor tends toward unity at high frequencies; the frequency dependence of the amplification is attributable to the depth of the soil column. As a general statement for firm-soil sites of unknown depth, the bedrock values should be multiplied by a factor of about 2. This does not account for any decreases in amplification that may be observed at large amplitudes because of nonlinear effects.
Table 2

Assumed Seismicity Parameters for Hazard Examples

\begin{tabular}{llll}
\hline \multicolumn{1}{c}{ Parameter } & \multicolumn{1}{c}{ Low Hazard } & \multicolumn{1}{c}{$\begin{array}{c}\text { Moderate } \\
\text { Hazard }\end{array}$} & \multicolumn{1}{c}{ High Hazard } \\
\hline$N(\mathbf{M} \geqq 4.5)$ & 0.0026 p.a. & 0.037 & 0.077 \\
Area & $50,000 \mathrm{~km}^{2}$ & 50,000 & 7000 \\
$N /$ Area & $1.6 \times 10^{-7}$ & $20 \times 10^{-7}$ & $257 \times 10^{-7}$ \\
$\beta(b)$ & $2.3(1.0)$ & $2.0(0.87)$ & $1.7(0.74)$ \\
$\mathbf{M}_{x}$ & 6.5 & 7.0 & 7.25 \\
\hline
\end{tabular}

Notes: $N(\mathbf{M} \geqq 4)$ is the number of events per annum with $\mathbf{M} \geqq$ 4 , in the quoted area. $N /$ Area gives the per annum rate of $\mathbf{M} \geqq 4$, per $\mathrm{km}^{2}, \beta$ is the slope of the magnitude recurrence relation $(b=\beta$ / $\ln 10$ ), and $M_{x}$ is the maximum assumed moment magnitude in the area. The standard deviation of the ground motion relations is assumed to be $0.25 \log$ (base 10) units.

\section{Comparison of Predictions to Data}

\section{Mean Residuals}

The ground-motion predictions (using the look-up table approach) are compared to response spectra data for ENA bedrock sites. Only mainshock data are used because aftershocks tend to have lower stress parameters (Boore and Atkinson, 1989; Atkinson, 1993a). The included events are listed in Table 4. Where necessary, vertical-component observations have been converted to the equivalent horizontal value using a relation derived from eastern seismographic recordings on rock (Atkinson, 1993b):

$$
\log H / V=0.0519+0.117 \log f
$$

The ground-motion data available for comparisons with the predictions should be considered a biased sample. ENA stress drops are highly variable. While most ENA earthquakes have stress drops in the range of 50 to 300 bars, 15 to $20 \%$ of events (three or four of 22 events studied, including Saguenay and Mont Laurier) have stress drops as high as 500 bars (Atkinson, 1993a). Records

\section{Table 3}

Soil Amplification Factor to Be Applied to Ground-Motion Relations for Rock, to Obtain Relations for Deep-Soil Sites (log PSA soil $=\log$ $\mathrm{PSA}_{\text {rock }}+\log$ factor)

\begin{tabular}{ccc}
$\begin{array}{l}\text { Frequency } \\
(\mathrm{Hz})\end{array}$ & Log Factor* & $\begin{array}{c}\text { Multiplicative } \\
\text { Factor }\end{array}$ \\
\hline 0.5 & 0.27 & 1.9 \\
1.0 & 0.27 & 1.9 \\
2.0 & 0.29 & 2.0 \\
5.0 & 0.24 & 1.7 \\
10.0 & 0.15 & 1.4 \\
20.0 & -0.03 & 0.93 \\
\hline
\end{tabular}

*Amplification factor is given in log units. 
Table 4

Summary of Data for Comparison with Ground-Motion Predictions

\begin{tabular}{lccccrcc}
\hline \multicolumn{1}{c}{ Event } & $(\mathrm{m} / \mathrm{d} / \mathrm{yr})$ & $\mathbf{M}$ & $M_{N}$ & $\mathbf{m}$ & $\begin{array}{c}\text { Stress } \\
\text { (bars) }\end{array}$ & $\begin{array}{c}\text { Number } \\
\text { of Obs. }\end{array}$ & Distance $(\mathrm{km})$ \\
\hline Gaza & $01 / 19 / 82$ & 4.0 & 4.8 & 3.7 & 86 & 5 & $200-1000$ \\
Goodnow & $10 / 07 / 83$ & 5.0 & 5.6 & 4.8 & 113 & 13 & $200-800$ \\
Nahanni & $12 / 23 / 85$ & 6.8 & 6.1 & 6.2 & 53 & 6 & $8-23$ \\
Painesville & $01 / 31 / 86$ & 4.8 & 5.3 & 4.8 & 149 & 9 & $20-1000$ \\
Ohio & $07 / 12 / 86$ & 4.5 & 4.9 & 4.5 & 154 & 5 & $700-1000$ \\
Saguenay FS & $11 / 23 / 88$ & 4.1 & 4.6 & 4.2 & 190 & 10 & $100-500$ \\
Saguenay & $11 / 25 / 88$ & 5.8 & 6.5 & 6.5 & 517 & 29 & $50-700$ \\
Mt. Laurier & $10 / 19 / 90$ & 4.7 & 5.1 & 5.4 & 517 & 14 & $30-500$ \\
\hline
\end{tabular}

Notes: only mainshocks are included. All records were obtained from the Geophysics Division of the Geological Survey of Canada. m $=2 \log A_{h f}+3$, where $A_{h f}$ is the high-frequency level of the Fourier spectrum of acceleration (horizontal component), in $\mathrm{cm} / \mathrm{s}$, at a distance of $10 \mathrm{~km}$ from the earthquake source (Atkinson and Hanks, 1995).

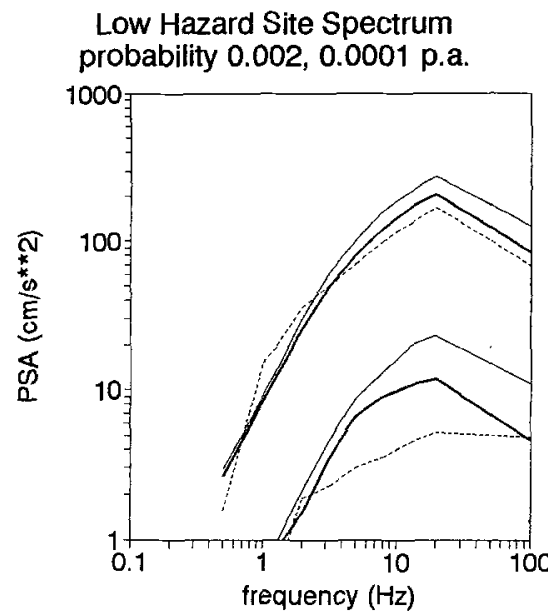

- AB94 table - AB94 eqn …... AB90 eqn
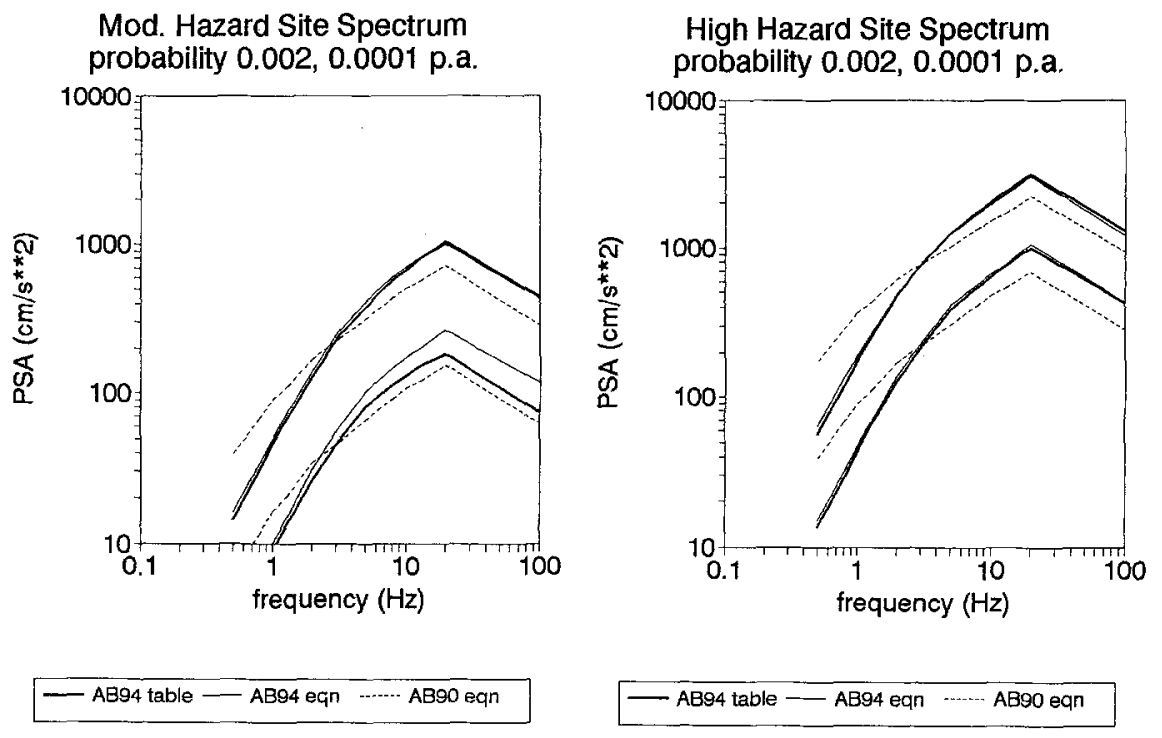

Figure 6. Comparison of results of probabilistic hazard analysis, for probabilities of 0.002 p.a. (lower lines) and 0.0001 p.a. (upper lines), obtained using "exact" ground-motion relations (heavy solid), new quadratic approximation (light solid), and the Atkinson and Boore (1990) relations (dotted). Comparisons are provided for areas of low, moderate, and high hazard. The expected PGA is plotted for reference at an arbitrary frequency of $100 \mathrm{~Hz}$, with an arbitrary straightline connection between the $20-\mathrm{Hz}$ PSA and the PGA.

Table 5

Total Random Variability in Ground Motions for ENA

\begin{tabular}{ccccc}
\hline \multirow{2}{*}{$\begin{array}{c}\text { Magnitude } \\
\text { Scale }\end{array}$} & \multicolumn{4}{c}{ Standard Deviation of Residuals for PSA } \\
\cline { 2 - 5 } & $1 \mathrm{~Hz}$ & $2 \mathrm{~Hz}$ & $5 \mathrm{~Hz}$ & $10 \mathrm{~Hz}$ \\
\hline$m_{N}$ & 0.43 & 0.34 & 0.31 & 0.29 \\
$\mathbf{M}$ & 0.24 & 0.24 & 0.26 & 0.27 \\
$\mathbf{m}$ & 0.31 & 0.30 & 0.23 & 0.24 \\
\hline
\end{tabular}

Notes: PSA is the $5 \%$ damped pseudo-acceleration. Residuals apply to rock sites, for mainshocks only. The variability (standard deviation of residuals, $\left.\sigma_{t}\right)$ was obtained as $\sigma_{t}=\sqrt{\left(\sigma_{1}^{2}+\sigma_{2}^{2}\right)}$, where the intraevent variability $\left(\sigma_{1}\right)$ is 0.20 for all cases. All numbers are log (base 10) units (from Atkinson, 1995). from the high-stress Saguenay and Mont Laurier events, tion, comprise nearly half of the ground-motion data base of Table 4-an important factor to consider when judging the residuals.

Figure 7 shows the differences between the observations and predictions as a function of $\mathbf{M}$; each point represents the average $\log$ residual for all stations recording an event. There is no systematic dependence on M. Average event residuals are generally within 0.15 $\log$ units $(40 \%)$ of zero, with the exception of the Saguenay ( $\mathbf{M}=5.8)$ earthquake, which has average residwhile representing only $20 \%$ of the earthquake popula- 
uals of about $0.35 \mathrm{log}$ units (factor of 2.2). Averaged over all eight events (equal-event weighting), the mean ( $\log$ ) residuals are $0.03,0.04,-0.03$, and -0.01 for frequencies of $1,2,5$, and $10 \mathrm{~Hz}$, respectively, with standard deviations of $0.13,0.14,0.17$, and 0.18 . Note these standard deviations represent only the interevent component of variability.

Figure 8 shows the differences between individual observations and predictions as a function of distance. The only apparent trend is a region of positive residuals at about $100 \mathrm{~km}$, which includes most of the Saguenay strong-motion records. Overall, the agreement between data and predictions appears satisfactory.

\section{Standard Deviation of Residuals}

The standard deviation of the $(\log )$ residuals $(\sigma)$, expressing the random variability of ground motions, is an important parameter for hazard analyses. In western North America, the observed value of $\sigma$ lies within the range of 0.2 to 0.3 (Boore et al., 1992). In ENA, the random variability depends partly on the magnitude scale used for ground-motion predictions (Atkinson, 1995). As shown in Table 5, the total random variability (interevent plus intraevent) for predictions from $\mathbf{M}$, based on the groundmotion data of Table 4, increases slightly with frequency from a value of $0.24 \log$ units at $1 \mathrm{~Hz}$ to 0.27 at $10 \mathrm{~Hz}$. Conversely, if predictions are based on the proposed highfrequency magnitude scale of Atkinson and Hanks (1995);
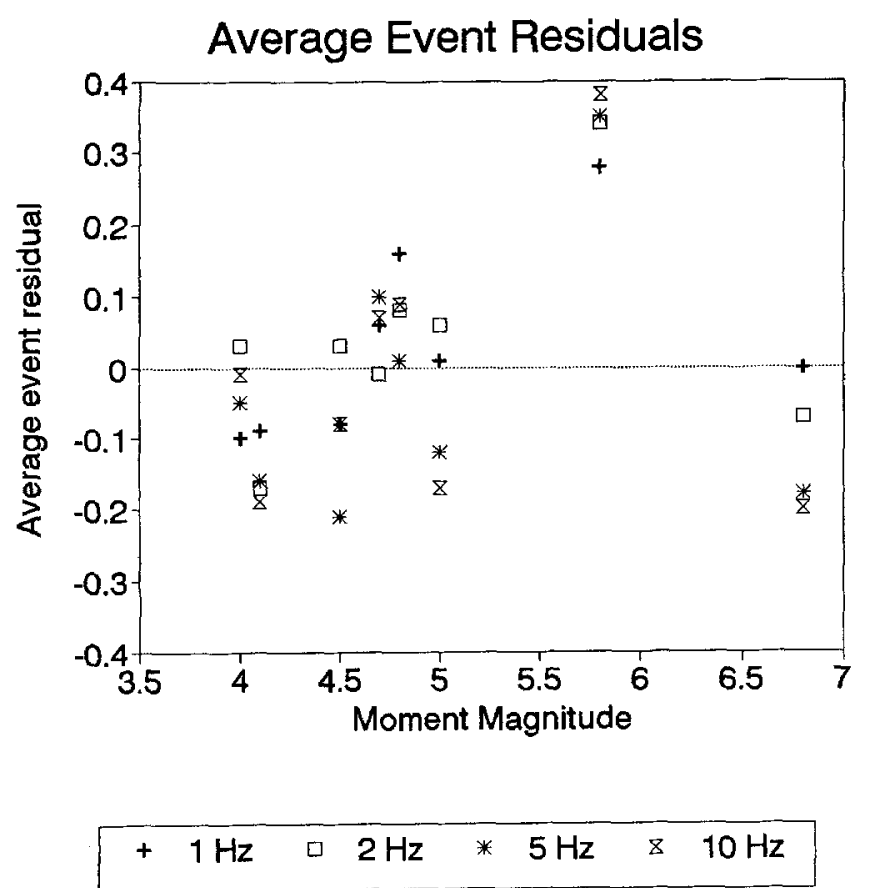

Figure 7. Average differences (mean event residuals in $\log$ units) between observed and predicted ground motions as a function of $\mathbf{M}$, for oscillator frequencies of $1,2,5$, and $10 \mathrm{~Hz}$ (mainshocks only). then variability decreases with frequency from 0.31 at 1 $\mathrm{Hz}$ to 0.24 at $10 \mathrm{~Hz}$. The variability for $m_{N}$-based predictions is large-about 0.3 to $0.4 \log$ units. This is a consequence of ambiguity in the relationship between $m_{N}$ and the source spectrum.

It is possible that high-stress events such as Saguenay and Mont Laurier represent a distinct subset of ENA source spectra. If so, it would be more appropriate to define separate ground-motion relations for "typical" and "high-stress" earthquakes, which would decrease the random variability associated with the relations. The two sets of relations could be appropriately weighted for use in hazard analyses. Current data are insufficient to determine whether this alternative approach is warranted.
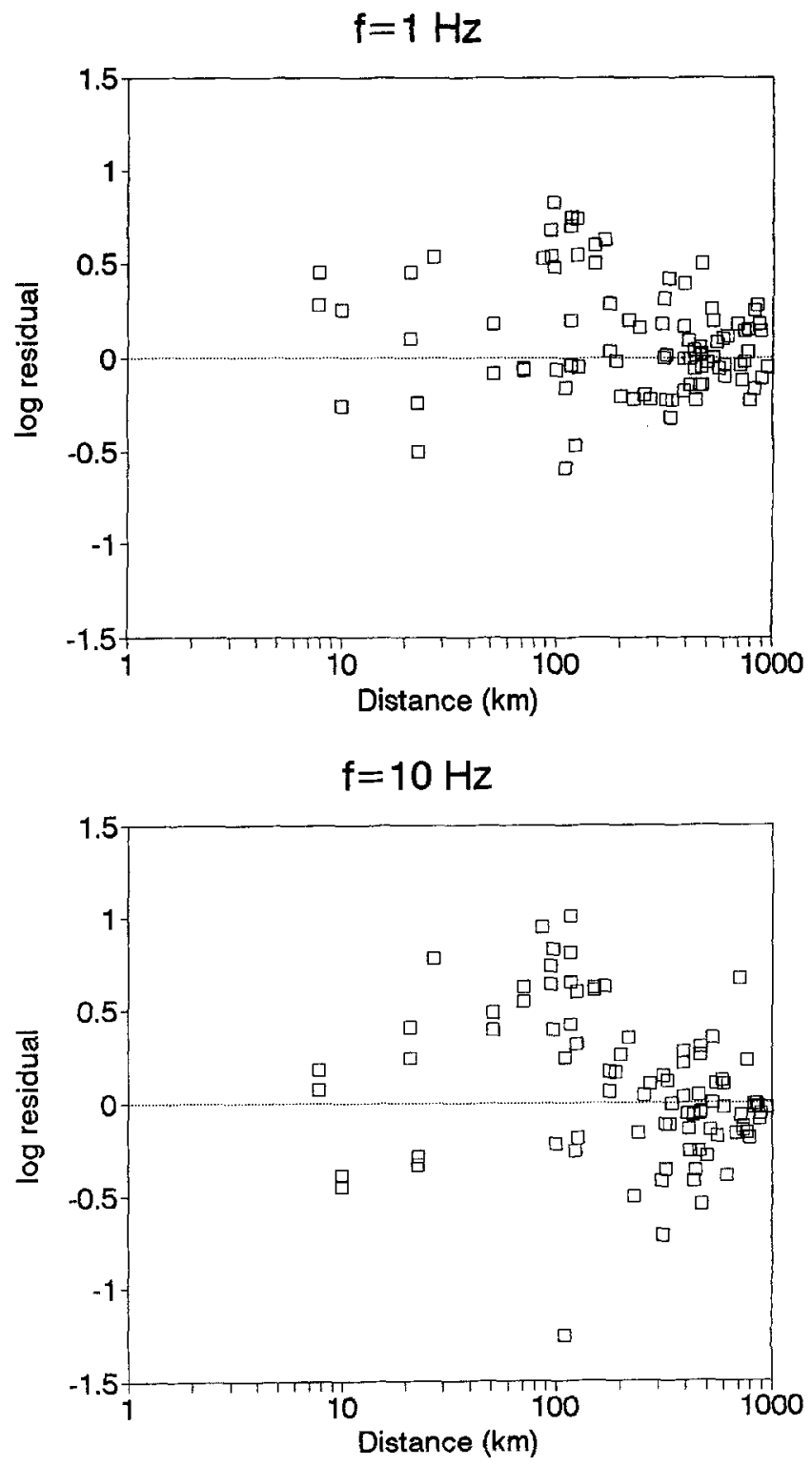

Figure 8. Differences (residuals in $\log$ units) between observed and predicted ground motions as a function of distance, for oscillator frequencies of 1 and $10 \mathrm{~Hz}$. 


\section{Conclusions}

The new ground-motion relations provide a good description of peak ground motions and response spectra for ENA earthquakes of small-to-moderate magnitude (M 4 to 5). There are insufficient strong-motion data to adequately judge the relations at larger magnitudes, although they appear to be consistent with the data from the Saguenay (M 5.8) and Nahanni (M 6.8) earthquakes. The underlying model parameters, such as the source spectrum and attenuation, are constrained by data for events of $\mathbf{M} 4$ to $\mathbf{M} 6.8$ and distances from 10 to 500 $\mathrm{km}$. This constraint on the model parameters, in combination with the demonstrated success of the model for small-to-moderate events, provides confidence that the predictions for large magnitudes are firmly based.

\section{Acknowledgments}

We have benefited from useful discussions with Bill Joyner, Tom Hanks, and members of the EPRI team, particularly Gabriel Toro. Constructive comments from Klaus Jacob and an anonymous reviewer were helpful in revising the article. The financial assistance of Ontario Hydro and the U.S. Nuclear Regulatory Commission is gratefully acknowledged.

\section{References}

Anderson, J. and S. Hough (1984). A model for the shape of the Fourier amplitude spectrum of acceleration at high frequencies, Bull. Seism. Soc. Am. 74, 1969-1993.

Atkinson, G. (1984). Attenuation of strong ground motion in Canada from a random vibrations approach, Bull. Seism. Soc. Am. 74, 2629-2653.

Atkinson, G. (1989). Attenuation of the $\mathrm{Lg}$ phase and site response for the Eastern Canada Telemetred Network, Seism. Res. Lett. 60, no. 2, 59-69.

Atkinson, G. (1993a). Source spectra for earthquakes in eastern North America, Bull. Seism. Soc. Am. 83, 1778-1798.

Atkinson, G. (1993b). Notes on ground motion parameters for eastern North America: duration and $\mathrm{H} / \mathrm{V}$ ratio, Bull. Seism. Soc. Am. 83, 587-596.

Atkinson, G. (1995). Optimal choice of magnitude scales for seismic hazard analysis, Seism. Res. Lett. in press.

Atkinson, G. and D. Boore (1990). Recent trends in ground motion and spectral response relations for North America, Earthq. Spectra, 6, 15-36.

Atkinson, G. and T. Hanks (1995). A high-frequency magnitude scale, Bull. Seism. Soc. Am., in press.

Atkinson, G. and R. Mereu (1992). The shape of ground motion attenuation curves in southeastern Canada, Bull. Seism. Soc. Am. 82, 2014-2031.

Boatwright, J. and G. Choy (1992). Acceleration source spectra anticipated for large earthquakes in Northeastern North America, Bull. Seism. Soc. Am., 82, 660-682.

Boore, D. (1983). Stochastic simulation of high-frequency ground motions based on seismological models of the radiated spectra, Bull. Seism. Soc. Am. 73, 1865-1894.

Boore, D. (1986). Short-period $P$ - and $S$-wave radiation from large earthquakes: implications for spectral scaling relations, Bull. Seism. Soc. Am. 76, 43-64.

Boore, D. and G. Atkinson (1987). Stochastic prediction of ground motion and spectral response parameters at hard-rock sites in eastern North America, Bull. Seism. Soc. Am. 77, 440-467.

Boore, D. and G. Atkinson (1989). Spectral scaling of the 1985-1988 Nahanni, Northwest Territories, earthquakes, Bull. Seism. Soc. Am. 79, 1736-1761.

Boore, D. and G. Atkinson (1992). Source spectra for the 1988 Saguenay, Quebec, earthquakes, Bull. Seism. Soc. Am. 82, 683719.

Boore, D. and W. Joyner (1991). Estimation of ground motion at deep-soil sites in eastern North America, Bull. Seism. Soc. Am. 81, 2167-2185.

Boore, D., W. Joyner, and L. Wennerberg (1992). Fitting the stochastic omega-squared source model to observed response spectra in western North America: trade-offs between stress drop and kappa, Bull. Seism. Soc. Am. 82, 1956-1963.

Brune, J. (1970). Tectonic stress and the spectra of seismic shear waves from earthquakes, J. Geophys. Res. 75, 4997-5009.

Burger, R., P. Somerville, J. Barker, R. Herrmann, and D. Helmberger (1987). The effect of crustal structure on strong ground motion attenuation relations in eastern North America, Bull. Seism. Soc. Am. 77, 420-439.

Campbell, K. (1991). An empirical analysis of peak horizontal acceleration for the Loma Prieta, California, earthquake of $18 \mathrm{Oc}-$ tober, 1989, Bull. Seism. Soc. Am. 81, 1838-1858.

Cornell, C. (1968). Engineering seismic risk analysis, Bull. Seism. Soc. Am. 58, 1583-1606.

EPRI (1988). Engineering model of earthquake ground motion for eastern North America, EPRI NP-6074, Electric Power Research Institute, Palo Alto, California.

EPRI (1993). Guidelines for determining design basis ground motions, Early site permit demonstration program, Vol. 1, RP3302, Electric Power Research Institute, Palo Alto, California.

Fletcher, J. and J. Boatwright (1991). Source parameters of Loma Prieta aftershocks and wave propagation characteristics along the San Francisco Peninsula from a joint inversion of digital seismograms, Bull. Seism. Soc. Am. 81, 1783-1812.

Hanks, T. (1982). $f_{\max }$, Bull. Seism. Soc. Am. 72, 1867-1879.

Hanks, T. and H. Kanamori (1979). A moment magnitude scale, $J$. Geophys. Res. 84, 2348-2350.

Hanks, T. and R. McGuire (1981). The character of high-frequency strong ground motion, Bull. Seism. Soc. Am. 71, 2071-2095.

McGuire, R. (1976). FORTRAN computer program for seismic risk analysis, U.S. Geol. Surv. Open-File Rept. 76-67.

McGuire, R. (1977). Seismic design spectra and mapping procedures using hazard analysis based directly on oscillator response, Int. J. Earthquake Eng. Struct. Dyn. 5, 211-234.

Mereu, R., D. Wang, O. Kuhn, D. Forsyth, A. Green, P. Morel, G. Buchbinder, D. Crossley, E. Schwarz, R. duBerger, C. Brooks, and R. Clowes (1986). The 1982 COCRUST seismic experiment across the Ottawa-Bonnechere graben and Grenville Front in Ontario and Quebec, Geophys. J. R. Astr. Soc. 84, 491-514.

Somerville, P., J. McLaren, L. Lefevre, R. Burger, and D. Helmberger (1987). Comparison of source scaling relations of eastern and western North American earthquakes, Bull. Seism. Soc. Am. 77, 322-346.

Somerville, P., J. McLaren, C. Saikia, and D. Helmberger (1990). The 25 November 1988 Saguenay, Quebec, earthquake: source parameters and the attenuation of strong ground motion, Bull. Seism. Soc. Am. 80, 1118-1143.

Street, R. and F. Turcotte (1977). A study of northeastern North American spectral moments, magnitudes, and intensities, Bull. Seism. Soc. Am. 67, 599-614.

Toro, G. and R. McGuire (1987). An investigation into earthquake ground motion characteristics in eastern North America, Bull. Seism. Soc. Am. 77, 468-489. 
Appendix

Table of 5\% Damped Pseudo-Acceleration Values $\left(\mathrm{cm} / \mathrm{sec}^{2}\right)$, Peak Ground Acceleration $\left(\mathrm{cm} / \mathrm{sec}^{2}\right)$, and Peak Ground Velocity $(\mathrm{cm} / \mathrm{sec})$ (ENA Median Horizontal Component: Rock Sites) (Atkinson and Boore, 1995)

\begin{tabular}{|c|c|c|c|c|c|c|c|c|c|c|c|}
\hline \multicolumn{12}{|c|}{ Moment $M=4.50$} \\
\hline \multirow[b]{2}{*}{$\log R$} & \multicolumn{11}{|c|}{ Log Values for Frequency $(\mathrm{Hz})=$} \\
\hline & 0.5 & 0.8 & 1.3 & 2.0 & 3.2 & 5.0 & 7.9 & 13.0 & 20.0 & PGA & PGV \\
\hline 1.00 & 0.48 & 0.75 & 1.04 & 1.40 & 1.74 & 2.08 & 2.34 & 2.56 & 2.70 & 2.41 & 0.56 \\
\hline 1.10 & 0.28 & 0.58 & 0.89 & 1.26 & 1.63 & 1.94 & 2.18 & 2.38 & 2.53 & 2.19 & 0.32 \\
\hline 1.20 & 0.08 & 0.38 & 0.72 & 1.11 & 1.48 & 1.76 & 2.04 & 2.23 & 2.34 & 2.00 & 0.11 \\
\hline 1.30 & -0.10 & 0.20 & 0.58 & 0.98 & 1.34 & 1.67 & 1.89 & 2.08 & 2.18 & 1.81 & -0.09 \\
\hline 1.40 & -0.31 & 0.04 & 0.48 & 0.83 & 1.20 & 1.53 & 1.71 & 1.90 & 2.00 & 1.64 & -0.26 \\
\hline 1.50 & -0.48 & -0.14 & 0.28 & 0.67 & 1.04 & 1.32 & 1.54 & 1.75 & 1.84 & 1.45 & -0.44 \\
\hline 1.60 & -0.62 & -0.22 & 0.18 & 0.57 & 0.88 & 1.18 & 1.41 & 1.56 & 1.64 & 1.26 & -0.62 \\
\hline 1.70 & -0.80 & -0.38 & 0.04 & 0.40 & 0.77 & 1.04 & 1.26 & 1.40 & 1.46 & 1.08 & -0.80 \\
\hline 1.80 & -0.92 & -0.52 & -0.10 & 0.26 & 0.59 & 0.89 & 1.08 & 1.20 & 1.30 & 0.87 & -0.96 \\
\hline 1.90 & -0.96 & -0.57 & -0.16 & 0.20 & 0.54 & 0.79 & 1.00 & 1.11 & 1.18 & 0.75 & -1.05 \\
\hline 2.00 & -1.00 & -0.62 & -0.19 & 0.18 & 0.48 & 0.79 & 0.95 & 1.08 & 1.11 & 0.68 & -1.08 \\
\hline 2.10 & -1.00 & -0.60 & -0.19 & 0.18 & 0.51 & 0.76 & 0.91 & 1.00 & 1.04 & 0.62 & -1.11 \\
\hline 2.20 & -1.06 & -0.68 & -0.25 & 0.08 & 0.41 & 0.64 & 0.79 & 0.88 & 0.87 & 0.45 & -1.22 \\
\hline 2.30 & -1.20 & -0.77 & -0.36 & -0.02 & 0.28 & 0.52 & 0.64 & 0.68 & 0.64 & 0.25 & -1.37 \\
\hline 2.40 & -1.30 & -0.85 & -0.47 & -0.11 & 0.15 & 0.36 & 0.45 & 0.41 & 0.26 & -0.01 & -1.52 \\
\hline 2.50 & -1.37 & -0.96 & -0.60 & -0.28 & -0.01 & 0.18 & 0.23 & 0.18 & -0.01 & -0.22 & -1.68 \\
\hline 2.60 & -1.52 & -1.08 & -0.72 & -0.42 & -0.18 & -0.04 & -0.01 & -0.11 & -0.31 & -0.46 & -1.87 \\
\hline 2.70 & -1.64 & -1.21 & -0.89 & -0.59 & -0.35 & -0.26 & -0.28 & -0.42 & -0.62 & -0.72 & -2.06 \\
\hline \multicolumn{12}{|c|}{ Moment $M=5.00$} \\
\hline & \multicolumn{11}{|c|}{ Log Values for Frequency $(\mathrm{Hz})=$} \\
\hline $\log R$ & 0.5 & 0.8 & 1.3 & 2.0 & 3.2 & 5.0 & 7.9 & 13.0 & 20.0 & PGA & PGV \\
\hline 1.00 & 0.73 & 1.00 & 1.32 & 1.68 & 2.08 & 2.34 & 2.57 & 2.74 & 2.90 & 2.57 & 0.75 \\
\hline 1.10 & 0.58 & 0.88 & 1.26 & 1.63 & 1.92 & 2.18 & 2.45 & 2.60 & 2.72 & 2.38 & 0.57 \\
\hline 1.20 & 0.43 & 0.74 & 1.11 & 1.45 & 1.79 & 2.04 & 2.28 & 2.45 & 2.58 & 2.21 & 0.40 \\
\hline 1.30 & 0.20 & 0.60 & 0.94 & 1.32 & 1.66 & 1.95 & 2.15 & 2.28 & 2.40 & 2.05 & 0.21 \\
\hline 1.40 & 0.11 & 0.52 & 0.86 & 1.20 & 1.53 & 1.79 & 1.98 & 2.15 & 2.26 & 1.88 & 0.04 \\
\hline 1.50 & 0.00 & 0.36 & 0.71 & 1.08 & 1.38 & 1.65 & 1.83 & 1.98 & 2.08 & 1.70 & -0.13 \\
\hline 1.60 & -0.18 & 0.23 & 0.58 & 0.98 & 1.28 & 1.48 & 1.67 & 1.82 & 1.90 & 1.52 & -0.30 \\
\hline 1.70 & -0.25 & 0.08 & 0.48 & 0.80 & 1.08 & 1.34 & 1.52 & 1.65 & 1.72 & 1.34 & -0.47 \\
\hline 1.80 & -0.40 & -0.03 & 0.28 & 0.64 & 0.96 & 1.20 & 1.36 & 1.46 & 1.54 & 1.13 & -0.64 \\
\hline 1.90 & -0.49 & -0.09 & 0.26 & 0.59 & 0.90 & 1.11 & 1.26 & 1.38 & 1.41 & 1.01 & -0.72 \\
\hline 2.00 & -0.49 & -0.09 & 0.26 & 0.59 & 0.87 & 1.11 & 1.23 & 1.32 & 1.36 & 0.95 & -0.73 \\
\hline 2.10 & -0.46 & -0.10 & 0.26 & 0.57 & 0.85 & 1.08 & 1.20 & 1.28 & 1.30 & 0.88 & -0.76 \\
\hline 2.20 & -0.54 & -0.17 & 0.15 & 0.48 & 0.76 & 0.95 & 1.08 & 1.15 & 1.11 & 0.73 & -0.88 \\
\hline 2.30 & -0.62 & -0.28 & 0.08 & 0.38 & 0.63 & 0.83 & 0.92 & 0.95 & 0.91 & 0.54 & -1.00 \\
\hline 2.40 & -0.72 & -0.38 & -0.04 & 0.23 & 0.51 & 0.64 & 0.72 & 0.69 & 0.53 & 0.28 & -1.16 \\
\hline 2.50 & -0.85 & -0.48 & -0.15 & 0.11 & 0.34 & 0.49 & 0.52 & 0.45 & 0.26 & 0.07 & -1.31 \\
\hline 2.60 & -0.89 & -0.55 & -0.29 & -0.04 & 0.18 & 0.30 & 0.28 & 0.18 & -0.01 & -0.15 & -1.46 \\
\hline 2.70 & -1.05 & -0.72 & -0.43 & -0.18 & -0.01 & 0.08 & 0.00 & -0.14 & -0.32 & -0.40 & -1.65 \\
\hline \multicolumn{12}{|c|}{ Moment $M=5.50$} \\
\hline & \multicolumn{11}{|c|}{ Log Values for Frequency $(\mathrm{Hz})=$} \\
\hline $\log R$ & 0.5 & 0.8 & 1.3 & 2.0 & 3.2 & 5.0 & 7.9 & 13.0 & 20.0 & PGA & PGV \\
\hline 1.00 & 0.94 & 1.28 & 1.65 & 2.00 & 2.32 & 2.58 & 2.80 & 2.93 & 3.08 & 2.72 & 0.93 \\
\hline 1.10 & 0.90 & 1.20 & 1.54 & 1.90 & 2.20 & 2.45 & 2.65 & 2.81 & 2.93 & 2.56 & 0.78 \\
\hline 1.20 & 0.76 & 1.08 & 1.45 & 1.78 & 2.11 & 2.34 & 2.52 & 2.65 & 2.79 & 2.41 & 0.63 \\
\hline 1.30 & 0.64 & 1.00 & 1.34 & 1.62 & 1.95 & 2.18 & 2.38 & 2.52 & 2.61 & 2.26 & 0.47 \\
\hline 1.40 & 0.51 & 0.86 & 1.20 & 1.51 & 1.83 & 2.04 & 2.26 & 2.36 & 2.46 & 2.10 & 0.32 \\
\hline 1.50 & 0.40 & 0.75 & 1.04 & 1.38 & 1.68 & 1.89 & 2.08 & 2.23 & 2.32 & 1.92 & 0.16 \\
\hline 1.60 & 0.26 & 0.60 & 0.95 & 1.28 & 1.56 & 1.76 & 1.94 & 2.04 & 2.15 & 1.75 & 0.00 \\
\hline 1.70 & 0.15 & 0.49 & 0.80 & 1.15 & 1.40 & 1.64 & 1.77 & 1.88 & 1.97 & 1.57 & -0.15 \\
\hline 1.80 & 0.00 & 0.34 & 0.67 & 0.99 & 1.26 & 1.48 & 1.60 & 1.72 & 1.78 & 1.37 & -0.33 \\
\hline 1.90 & -0.08 & 0.26 & 0.63 & 0.91 & 1.20 & 1.40 & 1.53 & 1.61 & 1.66 & 1.26 & -0.41 \\
\hline 2.00 & -0.05 & 0.28 & 0.58 & 0.90 & 1.18 & 1.36 & 1.49 & 1.58 & 1.60 & 1.19 & -0.43 \\
\hline 2.10 & -0.06 & 0.26 & 0.60 & 0.88 & 1.15 & 1.34 & 1.45 & 1.52 & 1.52 & 1.14 & -0.44 \\
\hline 2.20 & -0.11 & 0.20 & 0.52 & 0.81 & 1.08 & 1.23 & 1.34 & 1.38 & 1.34 & 0.97 & -0.54 \\
\hline 2.30 & -0.21 & 0.11 & 0.43 & 0.72 & 0.93 & 1.08 & 1.18 & 1.18 & 1.15 & 0.78 & -0.68 \\
\hline 2.40 & -0.30 & 0.04 & 0.34 & 0.58 & 0.81 & 0.93 & 0.97 & 0.93 & 0.77 & 0.56 & -0.81 \\
\hline 2.50 & -0.39 & -0.07 & 0.20 & 0.48 & 0.66 & 0.79 & 0.78 & 0.71 & 0.53 & 0.36 & -0.94 \\
\hline 2.60 & -0.48 & -0.21 & 0.04 & 0.30 & 0.49 & 0.57 & 0.54 & 0.43 & 0.26 & 0.13 & -1.12 \\
\hline 2.70 & -0.60 & -0.33 & -0.08 & 0.15 & 0.30 & 0.34 & 0.28 & 0.15 & -0.04 & -0.11 & -1.26 \\
\hline
\end{tabular}


Appendix-Continued

\begin{tabular}{|c|c|c|c|c|c|c|c|c|c|c|c|}
\hline \multicolumn{12}{|c|}{ Log Values for Frequency $(\mathrm{Hz})=$} \\
\hline $\log R$ & 0.5 & 0.8 & 1.3 & 2.0 & 3.2 & 5.0 & 7.9 & 13.0 & 20.0 & PGA & PGV \\
\hline 1.00 & 1.28 & 1.61 & 2.00 & 2.32 & 2.58 & 2.81 & 2.98 & 3.11 & 3.23 & 2.85 & 1.11 \\
\hline 1.10 & 1.18 & 1.53 & 1.86 & 2.18 & 2.45 & 2.66 & 2.83 & 2.98 & 3.08 & 2.71 & 0.97 \\
\hline 1.20 & 1.04 & 1.38 & 1.73 & 2.08 & 2.32 & 2.56 & 2.70 & 2.84 & 2.95 & 2.58 & 0.84 \\
\hline 1.30 & 0.95 & 1.28 & 1.61 & 1.93 & 2.20 & 2.43 & 2.58 & 2.72 & 2.81 & 2.43 & 0.69 \\
\hline 1.40 & 0.85 & 1.18 & 1.49 & 1.86 & 2.11 & 2.30 & 2.45 & 2.56 & 2.66 & 2.30 & 0.57 \\
\hline 1.50 & 0.71 & 1.04 & 1.38 & 1.67 & 1.94 & 2.15 & 2.32 & 2.41 & 2.51 & 2.12 & 0.41 \\
\hline 1.60 & 0.61 & 0.92 & 1.26 & 1.57 & 1.83 & 2.00 & 2.15 & 2.28 & 2.36 & 1.96 & 0.29 \\
\hline 1.70 & 0.45 & 0.80 & 1.15 & 1.43 & 1.70 & 1.86 & 2.00 & 2.11 & 2.20 & 1.79 & 0.11 \\
\hline 1.80 & 0.36 & 0.66 & 0.97 & 1.28 & 1.53 & 1.73 & 1.86 & 1.93 & 2.00 & 1.61 & -0.03 \\
\hline 1.90 & 0.28 & 0.61 & 0.92 & 1.23 & 1.45 & 1.64 & 1.77 & 1.83 & 1.89 & 1.50 & -0.11 \\
\hline 2.00 & 0.30 & 0.61 & 0.94 & 1.23 & 1.45 & 1.62 & 1.73 & 1.81 & 1.83 & 1.43 & -0.12 \\
\hline 2.10 & 0.30 & 0.60 & 0.92 & 1.20 & 1.43 & 1.59 & 1.68 & 1.75 & 1.76 & 1.36 & -0.14 \\
\hline 2.20 & 0.20 & 0.51 & 0.85 & 1.15 & 1.34 & 1.49 & 1.57 & 1.61 & 1.59 & 1.22 & -0.23 \\
\hline 2.30 & 0.11 & 0.43 & 0.73 & 1.00 & 1.23 & 1.34 & 1.43 & 1.43 & 1.40 & 1.03 & -0.36 \\
\hline 2.40 & 0.04 & 0.32 & 0.64 & 0.90 & 1.08 & 1.20 & 1.23 & 1.18 & 1.04 & 0.80 & -0.48 \\
\hline 2.50 & -0.04 & 0.26 & 0.53 & 0.78 & 0.94 & 1.04 & 1.04 & 0.94 & 0.76 & 0.62 & -0.61 \\
\hline 2.60 & -0.12 & 0.15 & 0.40 & 0.62 & 0.79 & 0.85 & 0.81 & 0.68 & 0.52 & 0.42 & -0.75 \\
\hline 2.70 & -0.23 & 0.04 & 0.30 & 0.48 & 0.61 & 0.60 & 0.53 & 0.38 & 0.23 & 0.17 & -0.89 \\
\hline \multirow{2}{*}{\multicolumn{12}{|c|}{ Log Values for Frequency $(\mathrm{Hz})=$}} \\
\hline & & & & & & & & & & & \\
\hline $\log R$ & 0.5 & 0.8 & 1.3 & 2.0 & 3.2 & 5.0 & 7.9 & 13.0 & 20.0 & PGA & PGV \\
\hline 1.00 & 1.56 & 1.88 & 2.23 & 2.53 & 2.77 & 2.94 & 3.15 & 3.26 & 3.36 & 2.98 & 1.27 \\
\hline 1.10 & 1.45 & 1.79 & 2.11 & 2.45 & 2.66 & 2.85 & 3.00 & 3.11 & 3.26 & 2.87 & 1.14 \\
\hline 1.20 & 1.32 & 1.69 & 2.00 & 2.30 & 2.56 & 2.72 & 2.91 & 3.00 & 3.11 & 2.74 & 1.05 \\
\hline 1.30 & 1.26 & 1.56 & 1.89 & 2.18 & 2.45 & 2.61 & 2.76 & 2.88 & 2.97 & 2.60 & 0.92 \\
\hline 1.40 & 1.15 & 1.48 & 1.78 & 2.08 & 2.32 & 2.51 & 2.65 & 2.74 & 2.85 & 2.46 & 0.81 \\
\hline 1.50 & 1.04 & 1.34 & 1.66 & 1.95 & 2.20 & 2.36 & 2.49 & 2.61 & 2.71 & 2.30 & 0.66 \\
\hline 1.60 & 0.89 & 1.23 & 1.53 & 1.86 & 2.08 & 2.23 & 2.36 & 2.46 & 2.54 & 2.16 & 0.52 \\
\hline 1.70 & 0.80 & 1.08 & 1.45 & 1.70 & 1.92 & 2.08 & 2.23 & 2.32 & 2.38 & 1.99 & 0.41 \\
\hline 1.80 & 0.66 & 0.97 & 1.32 & 1.58 & 1.80 & 1.95 & 2.04 & 2.15 & 2.23 & 1.82 & 0.23 \\
\hline 1.90 & 0.60 & 0.92 & 1.23 & 1.52 & 1.72 & 1.87 & 1.98 & 2.08 & 2.08 & 1.71 & 0.17 \\
\hline 2.00 & 0.60 & 0.95 & 1.23 & 1.49 & 1.70 & 1.85 & 1.97 & 2.00 & 2.04 & 1.64 & 0.15 \\
\hline 2.10 & 0.59 & 0.90 & 1.23 & 1.48 & 1.68 & 1.83 & 1.91 & 1.95 & 1.97 & 1.58 & 0.13 \\
\hline 2.20 & 0.53 & 0.83 & 1.15 & 1.40 & 1.59 & 1.71 & 1.79 & 1.81 & 1.81 & 1.44 & 0.05 \\
\hline 2.30 & 0.45 & 0.74 & 1.08 & 1.32 & 1.46 & 1.58 & 1.64 & 1.64 & 1.59 & 1.26 & -0.06 \\
\hline 2.40 & 0.36 & 0.66 & 0.97 & 1.20 & 1.36 & 1.45 & 1.45 & 1.40 & 1.23 & 1.05 & -0.19 \\
\hline 2.50 & 0.28 & 0.57 & 0.85 & 1.04 & 1.20 & 1.28 & 1.26 & 1.18 & 1.00 & 0.86 & -0.29 \\
\hline 2.60 & 0.18 & 0.46 & 0.71 & 0.92 & 1.04 & 1.08 & 1.04 & 0.91 & 0.76 & 0.66 & -0.42 \\
\hline 2.70 & 0.08 & 0.34 & 0.59 & 0.79 & 0.87 & 0.88 & 0.79 & 0.63 & 0.49 & 0.45 & -0.55 \\
\hline Moment $M$ & & & & & & & & & & & \\
\hline & & & & & $\log V_{a}$ & or Frequen & & & & & \\
\hline $\log R$ & 0.5 & 0.8 & 1.3 & 2.0 & 3.2 & 5.0 & 7.9 & 13.0 & 20.0 & PGA & PGV \\
\hline 1.00 & 1.81 & 2.18 & 2.48 & 2.74 & 2.98 & 3.15 & 3.28 & 3.40 & 3.51 & 3.13 & 1.45 \\
\hline 1.10 & 1.72 & 2.08 & 2.38 & 2.61 & 2.87 & 3.04 & 3.15 & 3.28 & 3.38 & 3.00 & 1.36 \\
\hline 1.20 & 1.61 & 1.96 & 2.28 & 2.56 & 2.75 & 2.90 & 3.04 & 3.15 & 3.26 & 2.87 & 1.23 \\
\hline 1.30 & 1.51 & 1.85 & 2.15 & 2.41 & 2.62 & 2.79 & 2.92 & 3.04 & 3.11 & 2.74 & 1.13 \\
\hline 1.40 & 1.41 & 1.74 & 2.04 & 2.32 & 2.51 & 2.65 & 2.81 & 2.92 & 3.00 & 2.62 & 0.99 \\
\hline 1.50 & 1.30 & 1.62 & 1.92 & 2.20 & 2.40 & 2.56 & 2.68 & 2.79 & 2.86 & 2.48 & 0.88 \\
\hline 1.60 & 1.20 & 1.53 & 1.84 & 2.08 & 2.28 & 2.43 & 2.54 & 2.64 & 2.73 & 2.33 & 0.74 \\
\hline 1.70 & 1.08 & 1.38 & 1.68 & 1.94 & 2.18 & 2.30 & 2.41 & 2.51 & 2.58 & 2.17 & 0.60 \\
\hline 1.80 & 0.95 & 1.28 & 1.58 & 1.83 & 2.04 & 2.15 & 2.28 & 2.34 & 2.38 & 1.99 & 0.48 \\
\hline 1.90 & 0.89 & 1.20 & 1.52 & 1.78 & 1.94 & 2.08 & 2.18 & 2.23 & 2.28 & 1.89 & 0.41 \\
\hline 2.00 & 0.87 & 1.18 & 1.51 & 1.76 & 1.91 & 2.04 & 2.15 & 2.20 & 2.20 & 1.83 & 0.39 \\
\hline 2.10 & 0.90 & 1.18 & 1.48 & 1.73 & 1.91 & 2.00 & 2.11 & 2.15 & 2.11 & 1.76 & 0.38 \\
\hline 2.20 & 0.81 & 1.11 & 1.40 & 1.64 & 1.83 & 1.92 & 1.99 & 2.00 & 1.98 & 1.62 & 0.30 \\
\hline 2.30 & 0.76 & 1.00 & 1.34 & 1.54 & 1.72 & 1.81 & 1.84 & 1.84 & 1.77 & 1.46 & 0.19 \\
\hline 2.40 & 0.64 & 0.97 & 1.26 & 1.49 & 1.59 & 1.68 & 1.67 & 1.60 & 1.46 & 1.27 & 0.10 \\
\hline 2.50 & 0.57 & 0.88 & 1.15 & 1.34 & 1.46 & 1.49 & 1.48 & 1.38 & 1.23 & 1.09 & 0.01 \\
\hline 2.60 & 0.49 & 0.76 & 1.00 & 1.20 & 1.30 & 1.32 & 1.26 & 1.11 & 0.98 & 0.89 & -0.12 \\
\hline 2.70 & 0.36 & 0.64 & 0.89 & 1.04 & 1.11 & 1.08 & 1.00 & 0.86 & 0.73 & 0.69 & -0.24 \\
\hline
\end{tabular}


Appendix-Continued

\begin{tabular}{|c|c|c|c|c|c|c|c|c|c|c|c|}
\hline \multicolumn{12}{|c|}{ Log Values for Frequency $(\mathrm{Hz})=$} \\
\hline $\log R$ & 0.5 & 0.8 & 1.3 & 2.0 & 3.2 & 5.0 & 7.9 & 13.0 & 20.0 & PGA & PGV \\
\hline 1.00 & 1.93 & 2.32 & 2.63 & 2.86 & 3.04 & 3.20 & 3.36 & 3.45 & 3.57 & 3.18 & 1.55 \\
\hline 1.10 & 1.83 & 2.18 & 2.51 & 2.74 & 2.96 & 3.11 & 3.23 & 3.34 & 3.45 & 3.08 & 1.43 \\
\hline 1.20 & 1.76 & 2.08 & 2.38 & 2.64 & 2.83 & 2.99 & 3.11 & 3.23 & 3.32 & 2.94 & 1.32 \\
\hline 1.30 & 1.62 & 1.98 & 2.28 & 2.54 & 2.74 & 2.89 & 2.99 & 3.11 & 3.20 & 2.82 & 1.21 \\
\hline 1.40 & 1.56 & 1.86 & 2.18 & 2.41 & 2.63 & 2.77 & 2.89 & 2.99 & 3.08 & 2.70 & 1.09 \\
\hline 1.50 & 1.45 & 1.79 & 2.08 & 2.30 & 2.51 & 2.64 & 2.78 & 2.86 & 2.93 & 2.55 & 0.98 \\
\hline 1.60 & 1.30 & 1.66 & 1.93 & 2.20 & 2.38 & 2.51 & 2.63 & 2.72 & 2.77 & 2.39 & 0.85 \\
\hline 1.70 & 1.20 & 1.54 & 1.84 & 2.08 & 2.26 & 2.38 & 2.49 & 2.58 & 2.62 & 2.25 & 0.74 \\
\hline 1.80 & 1.08 & 1.40 & 1.71 & 1.94 & 2.11 & 2.26 & 2.36 & 2.41 & 2.46 & 2.08 & 0.59 \\
\hline 1.90 & 1.04 & 1.34 & 1.66 & 1.89 & 2.04 & 2.18 & 2.28 & 2.34 & 2.38 & 1.97 & 0.53 \\
\hline 2.00 & 1.04 & 1.36 & 1.63 & 1.88 & 2.04 & 2.15 & 2.23 & 2.28 & 2.30 & 1.91 & 0.52 \\
\hline 2.10 & 0.99 & 1.32 & 1.61 & 1.86 & 2.04 & 2.11 & 2.20 & 2.23 & 2.23 & 1.85 & 0.51 \\
\hline 2.20 & 0.95 & 1.28 & 1.54 & 1.76 & 1.93 & 2.04 & 2.08 & 2.08 & 2.08 & 1.73 & 0.43 \\
\hline 2.30 & 0.86 & 1.18 & 1.46 & 1.66 & 1.81 & 1.91 & 1.94 & 1.94 & 1.86 & 1.57 & 0.32 \\
\hline 2.40 & 0.80 & 1.08 & 1.36 & 1.57 & 1.70 & 1.76 & 1.79 & 1.72 & 1.54 & 1.37 & 0.24 \\
\hline 2.50 & 0.71 & 1.04 & 1.28 & 1.46 & 1.56 & 1.60 & 1.58 & 1.48 & 1.32 & 1.19 & 0.14 \\
\hline 2.60 & 0.62 & 0.92 & 1.18 & 1.34 & 1.40 & 1.43 & 1.36 & 1.23 & 1.08 & 1.01 & 0.04 \\
\hline 2.70 & 0.52 & 0.80 & 1.04 & 1.18 & 1.20 & 1.20 & 1.11 & 0.98 & 0.85 & 0.81 & -0.09 \\
\hline
\end{tabular}

324 McLean Avenue

Arnprior, Ontario

Canada K7S 3T2

(G.M.A.)
U.S. Geological Survey

Menlo Park, California 94025

(D.M.B.) 